\title{
Thermal-death kinetics of fifth-instar Amyelois transitella (Walker) (Lepidoptera: Pyralidae)
}

\author{
S. Wang ${ }^{\mathrm{a}}$, J. Tang ${ }^{\mathrm{a}, *}$, J.A. Johnson ${ }^{\mathrm{b}}$, J.D. Hansen ${ }^{\mathrm{c}}$ \\ ${ }^{a}$ Department of Biological Systems Engineering, Washington State University, 213 L.J. Smith Hall, \\ Pullman, WA 99164-6120, USA \\ ${ }^{\mathrm{b}}$ USDA-ARS Horticultural Crops Research Laboratory, 2021 South Peach Avenue, Fresno, CA 93727, USA \\ ${ }^{\mathrm{c}}$ USDA-ARS Yakima Agricultural Research Laboratory, 5230 Konnowac Pass Road, Wapato, WA 98951, USA
}

Accepted 3 August 2001

\begin{abstract}
Information on kinetics for thermal mortality of navel orangeworm, Amyelois transitella (Walker) (Lepidoptera: Pyralidae), is needed for developing post-harvest phytosanitation thermal treatments of walnuts. Thermal-death kinetics for fifth-instar navel orangeworms were determined at temperatures between $46^{\circ} \mathrm{C}$ and $54^{\circ} \mathrm{C}$ at a heating rate of $18^{\circ} \mathrm{C} \mathrm{min}^{-1}$ using a heating block system. Thermal-death curves for fifth-instar navel orangeworms followed a 0.5 th-order of kinetic reaction. The time required to achieve $100 \%$ mortality $\left(N_{0}=600\right)$ decreased with increasing temperature in a logarithmic manner. Complete kill of 600 insects required a minimum exposure time of $140,50,15,6$, and $1 \mathrm{~min}$ at $46^{\circ} \mathrm{C}, 48^{\circ} \mathrm{C}, 50^{\circ} \mathrm{C}, 52^{\circ} \mathrm{C}$, and $54^{\circ} \mathrm{C}$, respectively. The reaction rate $(k)$ was affected by treatment temperatures following an Arrhenius relationship. The activation energy for thermal kill of fifth-instar navel orangeworms was estimated to be between 510 and $520 \mathrm{~kJ} \mathrm{~mol}^{-1}$. (C) 2002 Elsevier Science Ltd. All rights reserved.

Keywords: Navel orangeworm; Thermal-death kinetics; Heat treatment; Activation energy; Heating block; Insect pest; Phytosanitary treatment
\end{abstract}

\section{Introduction}

California produces nearly all of the walnuts and almonds in the United States, resulting in an annual production of $>650,000$ ton, $30 \%$ of which is for export (USDA, 1999). A major problem in production, storage, and marketing of almonds and walnuts in California is infestation by navel orangeworm, Amyelois transitella (Walker) (Lepidoptera: Pyralidae), (Wade, 1961). Larvae

\footnotetext{
*Corresponding author. Tel.: + 1-509-335-2140; fax: + 1-509-335-2722.

E-mail address: jtang@mail.wsu.edu (J. Tang)
} 
of this field pest feed directly on nutmeats and may be present in harvested product, where they cause post-harvest commodity losses through feeding and by contaminating product with frass and webbing. Although navel orangeworm does not normally reproduce under storage conditions, larvae may move to undamaged nuts and continue to feed while in storage. Post-harvest treatments are therefore required to prevent additional product damage by this insect during storage and to ensure uninfested products before shipment to domestic and international markets. Currently, the dried fruit and tree nut industry relies heavily on fumigation with methyl bromide and phosphine (hydrogen phosphide) for post-harvest insect control (Carpenter et al., 2000). However, the Montreal Protocol (UNEP, 1992) has identified methyl bromide as an ozone depleter, which has resulted in a gradual annual reduction and eventual elimination of most uses of methyl bromide. Insect resistance to hydrogen phosphide has been documented in other commodities (Zettler et al., 1989), and the United States Environmental Protection Agency (USEPA) is considering increased restrictions on the use of hydrogen phosphide (USEPA, 1998). Although non-chemical treatments for post-harvest dried fruits and nuts have been investigated in the past to some extent (Storey and Soderstrom, 1977), little progress has been made and concerns over resistance and regulatory action have generated a renewed interest in developing alternative treatments.

Several alternative methods have been suggested, including ionizing radiation (Johnson and Marcotte, 1999), cold storage (Johnson et al., 1997), controlled atmospheres (Brandl et al., 1983), and combination treatments (Johnson et al., 1998). All would require substantial capital investment and alteration of existing facilities. Cold storage and controlled atmospheres also require lengthy treatment times for disinfestation, and there is concern over public acceptance of irradiated food. Heat treatments have been proposed to kill codling moth in different commodities using forced hot air or hot water dips (Yokoyama et al., 1991; Jones and Waddell, 1997), but the lengthy exposure times needed may cause injury to the product (Lurie, 1998). Industrial radio frequency and microwave systems, extensively used in the food processing, textile and wood processing industries, may provide more rapid product heating $\left(10-20^{\circ} \mathrm{C} \mathrm{min}^{-1}\right)$ and have been suggested for control of post-harvest insects (Andreuccetti et al., 1994; Hallman and Sharp, 1994; Nelson, 1996; Tang et al., 2000; Wang et al., 2001). Knowledge of thermal-death kinetics for targeted insects is essential in developing those thermal treatments. But no thermaldeath-kinetic data for navel orangeworm have been reported in the literature.

Probit analysis and thermal kinetics models have been commonly used to study thermal resistance of insect pests. The former method is based on the assumption that the frequency of individual death in an insect population under constant temperatures follows the standard normal distribution over time. Although it is useful to confirm the effectiveness of quarantine treatments, it may not be appropriate for developing new thermal methods because the information may not easily be extrapolated for the purpose of predicting mortality in new test conditions (Tang et al., 2000). Thomas and Mangan (1997) reviewed several models for Mexican fruit flies. They recommended the use of a thermal dynamic model to estimate quarantine treatment levels when developing new thermal-treatment methods.

Several methods have been reported for studying thermal-death kinetics of insects. These methods include directly exposing insects in a water bath for specific times, heating insects in tubes which in turn are submerged in a water bath, or heating insects in fruits (Yokoyama et al., 1991; Thomas and Mangan, 1997; Waddell et al., 2000). A heating block system was developed at Washington State University (WSU), Pullman WA, to study thermal-death kinetics of codling 
moth (Ikediala et al., 2000). This system was able to heat exposed insects directly and simulate different heating rates from $1{ }^{\circ} \mathrm{Cmin}^{-1}$ to $20^{\circ} \mathrm{Cmin}^{-1}$ accurately. This system avoided possible insect drowning experienced in tests in which insects were immersed in water baths. However, the previous WSU system could only hold a maximum of 50 larvae, and the small test cavity size made handling insects difficult.

The objectives of this study were: (1) to develop an improved heating block system and use this system to study temperature effects on thermal mortality of fifth-instar navel orangeworm and (2) to model the kinetics for thermal kill of navel orangeworms.

\section{Materials and methods}

\subsection{Description of the heating block system}

The previous WSU heating block system (Ikediala et al., 2000) was modified to handle more insects, to easily keep the actively moving insects in the chamber during handling of insects, and to control the test chamber gas composition. The system consisted of top and bottom blocks, heating pads, an insect test chamber, controlled atmosphere circulating channels (not used in this study), and a data acquisition/control unit (Strawberry Tree Inc., Sunnyvale, CA) (Fig. 1). The heating block unit was placed in an insulation box to prevent heat loss during the tests. The heating blocks were made of aluminum alloys with low thermal capacitance $\left(903 \mathrm{~J} \mathrm{~kg}^{-1}{ }^{\circ} \mathrm{C}^{-1}\right)$ and high thermal conductivity $\left(234 \mathrm{~W} \mathrm{~m}^{-1 \circ} \mathrm{C}^{-1}\right)$. To obtain heating rates of up to $20^{\circ} \mathrm{C} \mathrm{min}^{-1}$ and to handle 200 insects at a time, the two heating blocks were enlarged to $254 \times 254 \times 18 \mathrm{~mm}^{3}$. The height of the

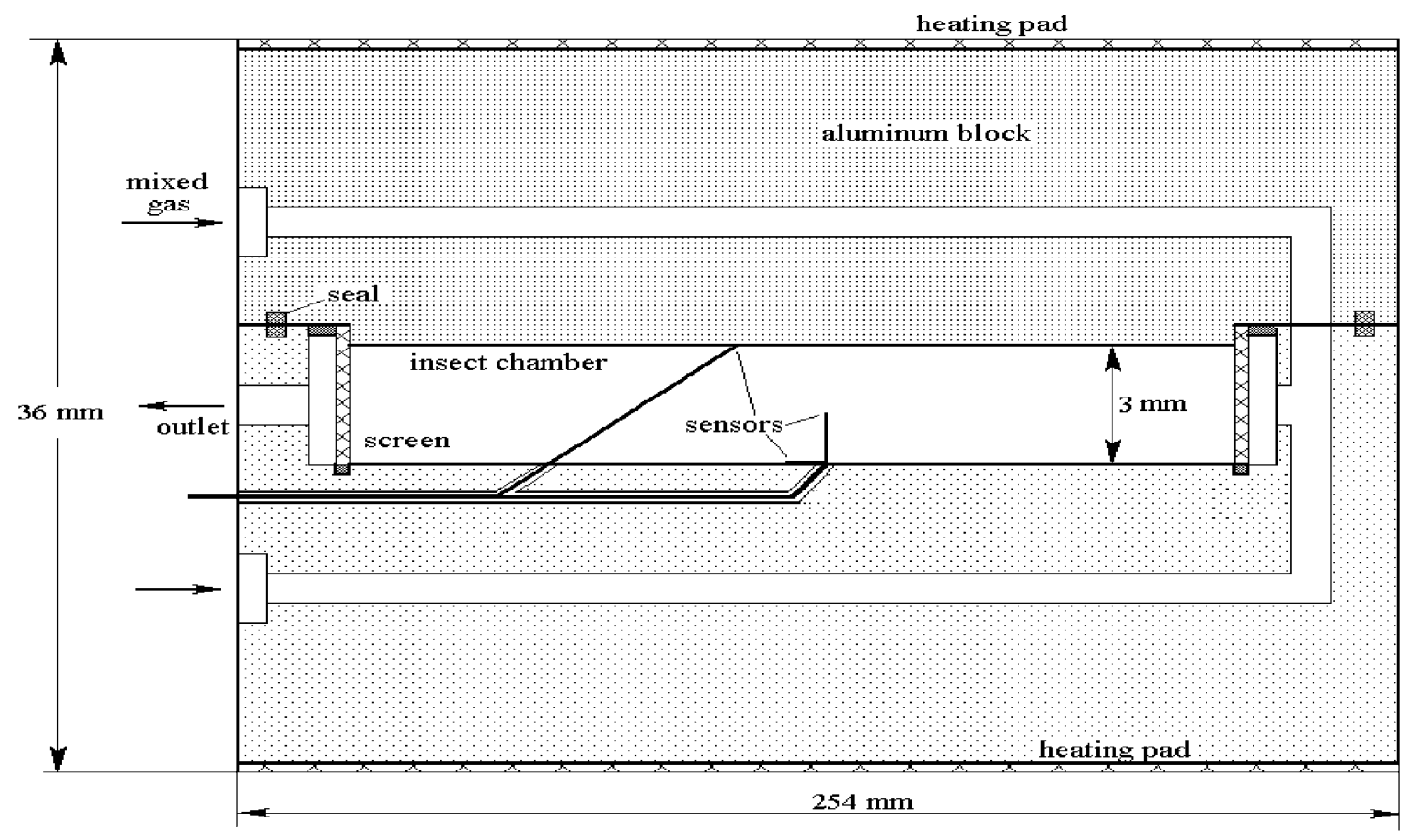

Fig. 1. Diagram of the new WSU heating block system for insect mortality studies. 
insect chamber can be varied from 3 to $6 \mathrm{~mm}$ by adding/moving a piece of aluminum plate on the top block to provide contact between the insect chamber and the block surfaces. The height of $3 \mathrm{~mm}$ was used in this study, based on the size of fifth-instar navel orangeworms. Eight custommade heating pads $(250 \mathrm{~W})$ were glued to the top and bottom block surfaces, providing a maximum heating flux density of $15,500 \mathrm{~W} \mathrm{~m}^{-2}$. The insect thermal-death results can be influenced by the system control precision. Calibrated type-T thermocouples inserted through sensor paths were used to monitor the temperatures of the top and bottom plates, and the air temperature in the chamber. Heating rate $\left(0.1^{\circ} \mathrm{C} \mathrm{min}^{-1}\right.$ to $\left.20^{\circ} \mathrm{Cmin}^{-1}\right)$ and the set-point temperature were controlled by the visual software WorkBench PC 2.0 (Strawberry Tree Inc., Sunnyvale, CA) via a solid-state relay. Two on-off controllers regulated the two block surface temperatures separately. Power supply to the heating pads was regulated by the number of electric pulses in microsecond time intervals. The thermal capacitance of the blocks provided smooth temperature profiles over the heating and holding periods (Ikediala et al., 2000). As we chose to examine only the effect of heat in this study, the mixed gas channel was closed.

\subsection{Test insects}

Navel orangeworms were reared at the USDA Horticultural Crops Research Laboratory, Fresno, CA, on a wheat bran diet (Tebbets et al., 1978) at $27^{\circ} \mathrm{C}, 60 \%$ r.h. and a photoperiod of 14:10 (L:D) h. Before treatment, fifth-instars were placed in plastic cups $(475 \mathrm{ml})$ with diet, packed in an insulated shipping carton, and shipped via overnight delivery to Washington State University, Pullman, WA. Upon arrival the insects were transferred to glass jars (1.651) and left at room temperature for several hours before testing. We used only actively moving fifth-instar larvae in tests. We used larvae at this life-stage because of their large size and ease in handling, and to allow comparison with fifth-instar codling moth larvae. Other life-stages will be tested in later studies.

\subsection{Procedures}

A heating rate of $18^{\circ} \mathrm{Cmin}^{-1}$ was selected to simulate rapid heating of fruits using radio frequency and microwave energies. Five treatment temperatures from $46^{\circ} \mathrm{C}$ to $54^{\circ} \mathrm{C}$ with $2^{\circ} \mathrm{C}$ increments and four to seven holding times $(0.5$ to $140 \mathrm{~min})$ were selected as test conditions, based on the thermal-death-time (TDT) curve for fifth-instar codling moth larvae (Ikediala et al., 2000). The holding time intervals at $54^{\circ} \mathrm{C}$ were determined first and the time intervals were increased at lower temperatures to have a 10-20\% mortality difference between two consecutive treatments. At each temperature, four to seven holding times were selected to provide a wide range of mortality levels, including $100 \%$. During the preliminary tests, we found that the mortality observed in the control insects was mainly caused by handling, and that prolonged exposures in the unheated block added little if any additional mortality. Consequently, control larvae were placed in the unheated block chamber for $5 \mathrm{~min}$ to reduce test time. For each temperature and holding time combination, including controls, 200 larvae were treated at a time and all treatments were repeated 3 times for a total of 600 larvae.

At the end of each holding time, the power to the heating block was turned off and the insects were quickly $(<10 \mathrm{~s})$ transferred to a plastic container. Cardboard strips were provided for resting sites. Because we anticipated that commercial treatments would include rapid post-treatment 
cooling of product to minimize the effect on product quality, the treated larvae were immediately moved to cold storage at $4^{\circ} \mathrm{C}$ and stored at this temperature for 1 day. After the cold storage, the larvae were held at $23^{\circ} \mathrm{C}, 60 \%$ r.h. and a 14:10 (L:D) h photoperiod for 1 day to minimize the effect of cold stupor before examination. Insects were considered dead if no movement and changed body color were observed. Moribund and surviving larvae were observed for an additional 5 days. The level of pupation or adult emergence was not used in the evaluation because the time to pupation and adult emergence took several weeks.

Mortality was calculated as the percentage of dead larvae relative to total treated larvae for each treatment. Mean values and standard deviations were obtained from three replications for each temperature-time combination. Thermal-mortality curves, expressed as the logarithmic value of the ratio of the initial number of insects $\left(N_{0}\right)$ to the number of surviving insects $(N)$ versus the exposure time, were developed for each treatment temperature. Where mortality was $100 \%$, a value of 0.1 was used for $N$. The standard deviation was used to plot the error bar at each treatment level.

\subsection{Empirical model for thermal-mortality kinetics}

The thermal mortality data were described by the following empirical equation established by Alderton and Snell (1970):

$$
\left(\log \frac{N_{0}}{N}\right)^{a}=k t+c
$$

where $N_{0}$ and $N$ are the initial and surviving numbers of insects, $t$ is the holding time (min) at a fixed temperature, $k$ is the thermal-death-rate constant $\left(\min ^{-1}\right), a$ and $c$ are constants. This equation was fitted to experimental data by two steps: (1) obtain a best value for the exponential constant $a$ using multiple linear regression for data at all temperatures; (2) after fixing $a$, determine values of $c$ and $k$ by linear regression with $\left[\log \left(N_{0} / N\right)\right]^{a}$ as the dependent variable and $t$ as an independent variable for each temperature. The resulting equations were used to estimate the lethal time to reach $95 \%, 99 \%, 99.83 \%$, and Probit 9 mortality $\left(\mathrm{LT}_{95}, \mathrm{LT}_{99}, \mathrm{LT}_{99.83}\right.$, and $\mathrm{LT}_{99.9968}$ ) for the insects at each temperature. $\mathrm{LT}_{95}, \mathrm{LT}_{99}$, and $\mathrm{LT}_{99.9968}$ are commonly reported mortality levels in the literature, and the estimated $\mathrm{LT}_{99.83}$ closely corresponded to the observed exposures that produced a complete kill of 600 insects.

The value of $k$ changes with temperature, following an Arrhenius relationship

$$
k=k_{r e f} \mathrm{e}^{\left(-E_{a} / R\right)\left((1 / T)-\left(1 / T_{r e f}\right)\right)},
$$

where $T$ is the absolute temperature $\left({ }^{\circ} \mathrm{K}\right), k_{\text {ref }}$ is the thermal-death-rate constant at the reference temperature $T_{r e f}\left({ }^{\circ} \mathrm{K}\right), E_{a}$ is the activation energy $\left(\mathrm{J} \mathrm{mol}^{-1}\right)$, and $R$ is the universal gas constant $\left(8.314 \mathrm{~J} \mathrm{~mol}^{-1}{ }^{\circ} \mathrm{K}^{-1}\right)$. The activation energy for thermal inactivation of test larvae was calculated from the slope of an Arrhenius plot of $\log k$ versus the reciprocal of the absolute temperature $(1 / T)$.

\subsection{TDT curve}

A thermal-death-time (TDT) curve for navel orangeworm was developed by plotting the minimum exposure time required at each temperature to achieve $100 \%$ kill of test larvae on a 
semi-log scale. This type of plot was used to describe thermal kinetics of codling moth by Ikediala et al. (2000). The $z$ value (the temperature difference by which the minimum temperature-time to achieve $100 \%$ kill is altered by a factor of 10) was obtained from the TDT curve as described in Tang et al. (2000). The activation energy needed for thermal death of test larvae was related to the $z$ value according to the following relationship (Tang et al., 2000):

$$
E_{a}=\frac{2.303 R T_{\min } T_{\text {max }}}{z},
$$

where $T_{\min }$ and $T_{\max }$ are the minimum and maximum temperatures $\left({ }^{\circ} \mathrm{K}\right)$ of a test range, respectively.

\subsection{Fundamental kinetic model}

The empirical kinetic model (Eq. (1)) can be considered as a modification of the 1st-order reaction relationship by adding an exponential constant $(a)$ to improve the curve fitting. The constant $(a)$, however, did not carry any obvious information to help interpret the thermal-death kinetics of insects. A fundamental kinetic model was attempted in this study to determine the order of reaction for thermal kill of insects. Basically, the rate of change in the ratio of insect survivals to initial insect number during thermal treatments can be modeled as following the fundamental kinetic model:

$$
\frac{\mathrm{d}\left(N / N_{0}\right)}{\mathrm{d} t}=-k\left(N / N_{0}\right)^{n},
$$

where $n$ is the kinetic order of the reaction. The integration form of Eq. (4) can be obtained for different reaction orders as follows:

$$
\begin{array}{ll}
\ln \left(N / N_{0}\right)=-k t+c & (n=1), \\
\left(N / N_{0}\right)^{1-n}=-k t+c & (n \neq 1) .
\end{array}
$$

A linear regression analysis was performed for the $0-, 0.5$ th-, 1 st-, 1.5 th-, and 2 nd-order of thermal reaction. The order of reaction was determined by comparing the coefficients of determination $\left(R^{2}\right)$ for all the treated temperatures. After the reaction order was determined, and the values of $k$ and $c$ were obtained, Eq. (4) was used to estimate the lethal time $\mathrm{LT}_{95}, \mathrm{LT}_{99}, \mathrm{LT}_{99.83}$, and $\mathrm{LT}_{99.9968}$. The activation energy for thermal inactivation of test larvae was calculated from the relationship between $k$ and $T$ on an Arrhenius plot according to Eq. (2).

\section{Results and discussion}

\subsection{Heating characteristics of the test unit}

The calibration curves for the three type-T thermocouples used to measure the air, top and bottom plate temperatures are illustrated in Fig. 2. The linear regression equations for top and bottom plate sensors against the air temperature sensor $\left(T_{i}\left({ }^{\circ} \mathrm{C}\right)\right)$ were $-0.102+1.006 T_{i}$ and $0.137+1.002 T_{i}$ with both $R^{2}=0.99$. These results were considered to be adequately accurate for monitoring and controlling the heating rate, set-point temperature, and exposure time. The 


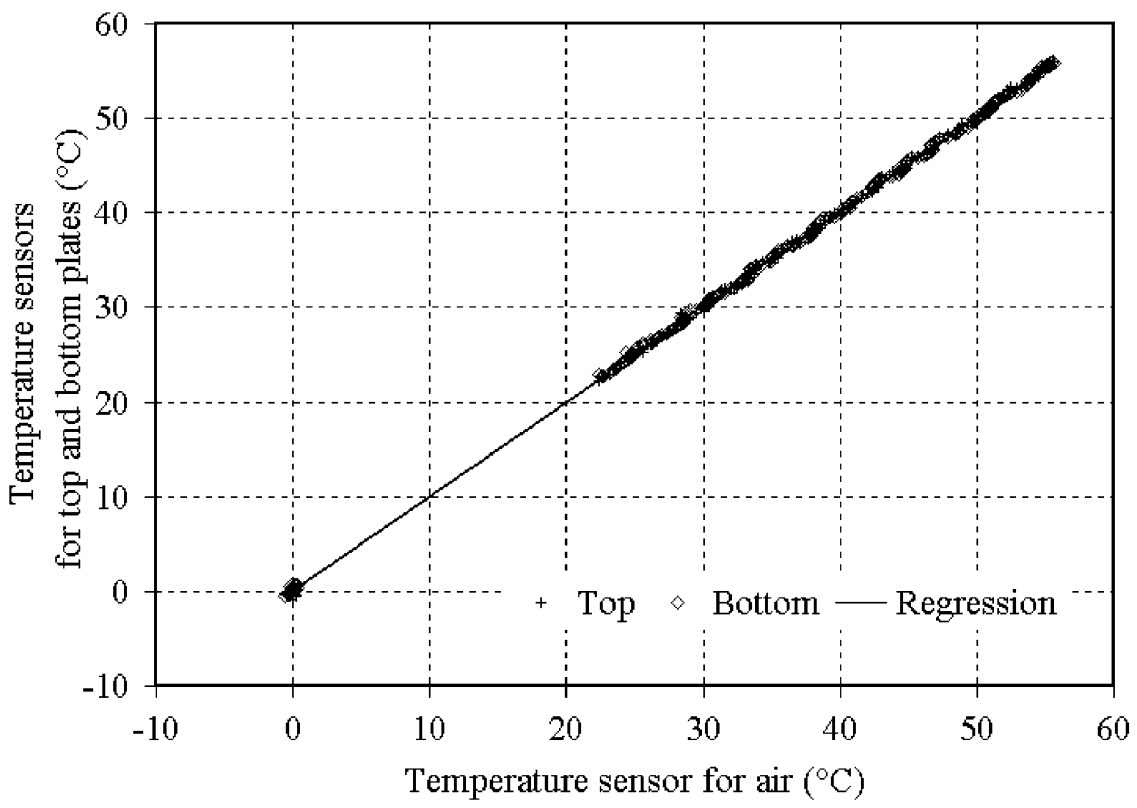

Fig. 2. Calibration curves for thermocouples measuring the air, top and bottom plate temperatures of the WSU heating block system.

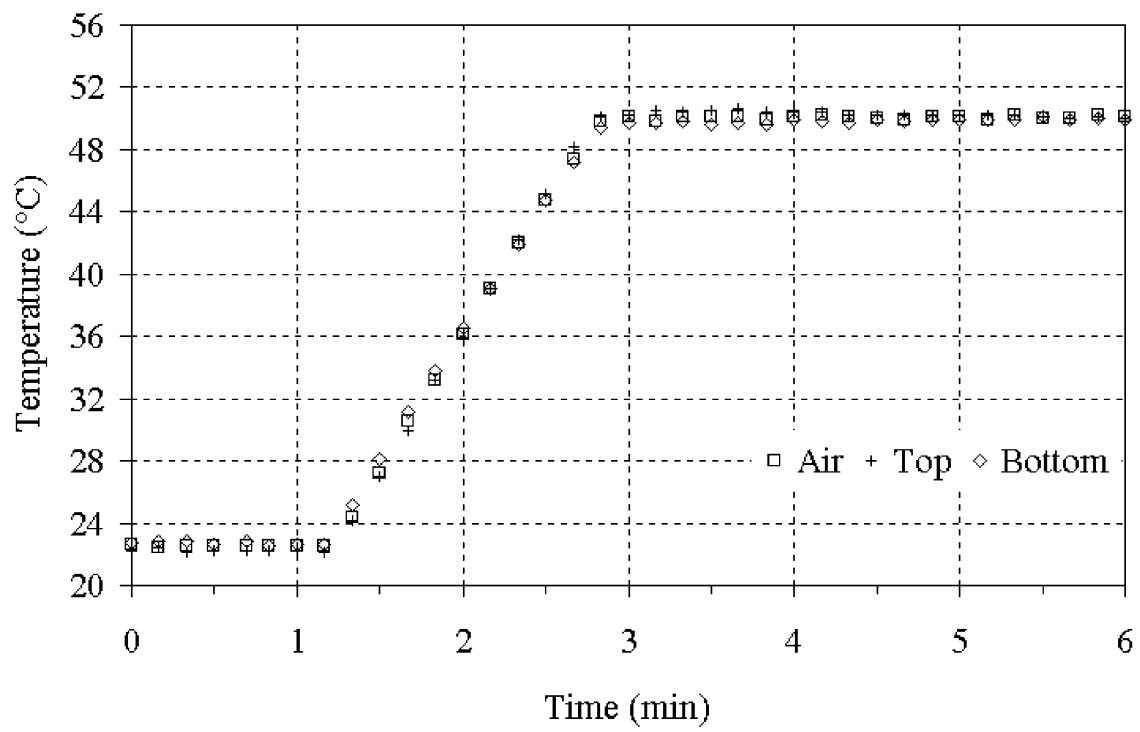

Fig. 3. The air, top and bottom plate temperatures of the heating block system when heated to $50^{\circ} \mathrm{C}$ at a rate of $18^{\circ} \mathrm{Cmin}^{-1}$.

temperature profiles of the block surfaces and the air inside the empty insect chamber are shown in Fig. 3 for a heating rate of $18^{\circ} \mathrm{Cmin}^{-1}$ from ambient to a set-point temperature of $50^{\circ} \mathrm{C}$. Experimental temperatures for the three positions were very close. At the final temperature 
of the exposure period, air, top and bottom plate temperatures deviated from the set point by $0.1^{\circ} \mathrm{C}, 0.2^{\circ} \mathrm{C}$, and $0.1^{\circ} \mathrm{C}$, respectively.

\subsection{Thermal-mortality curves}

The survival in unheated controls was high $(97.3 \pm 1.6 \%)$, suggesting negligible effect of shipping and handling. Consequently, mortality data for the thermal treatments were not corrected by the control mortality. Thermal-mortality values as a function of time at temperatures of $46^{\circ} \mathrm{C}, 48^{\circ} \mathrm{C}, 50^{\circ} \mathrm{C}, 52^{\circ} \mathrm{C}$, and $54^{\circ} \mathrm{C}$ are presented in Fig. 4 . The data exhibited a non-logarithmic trend. At lower temperatures, thermal-mortality curves typically followed a rather broad shoulder, and then dropped rapidly. At higher temperatures, the initial shoulder of the curves was negligible and the survival number decreased linearly on a semi-log plot almost directly from the onset. Brief exposure to $54^{\circ} \mathrm{C}$ caused rapid death of the insects, as $100 \%$ mortality in three samples of 200 was reached after only 1 min holding. The higher the temperature, the shorter the exposure needed to kill all insects.

The thermal-mortality regression curves for navel orangeworm at different temperatures were obtained using Eq. (1). The constants in Eq. (1) at different temperatures are presented in Table 1. Ideally, the value of $c$ should be equal to zero so that the fitted curve passed through the origin of the coordinate (i.e., $\log \left(N_{0} / N\right)=0$ at $t=0$ ). In reality, however, the best-fitted curve may not pass this point as shown in Table 1 because of non-zero mortality at the beginning of treatments. The thermal-death-rate constant $k$ increased with the temperature. The established relationship can be

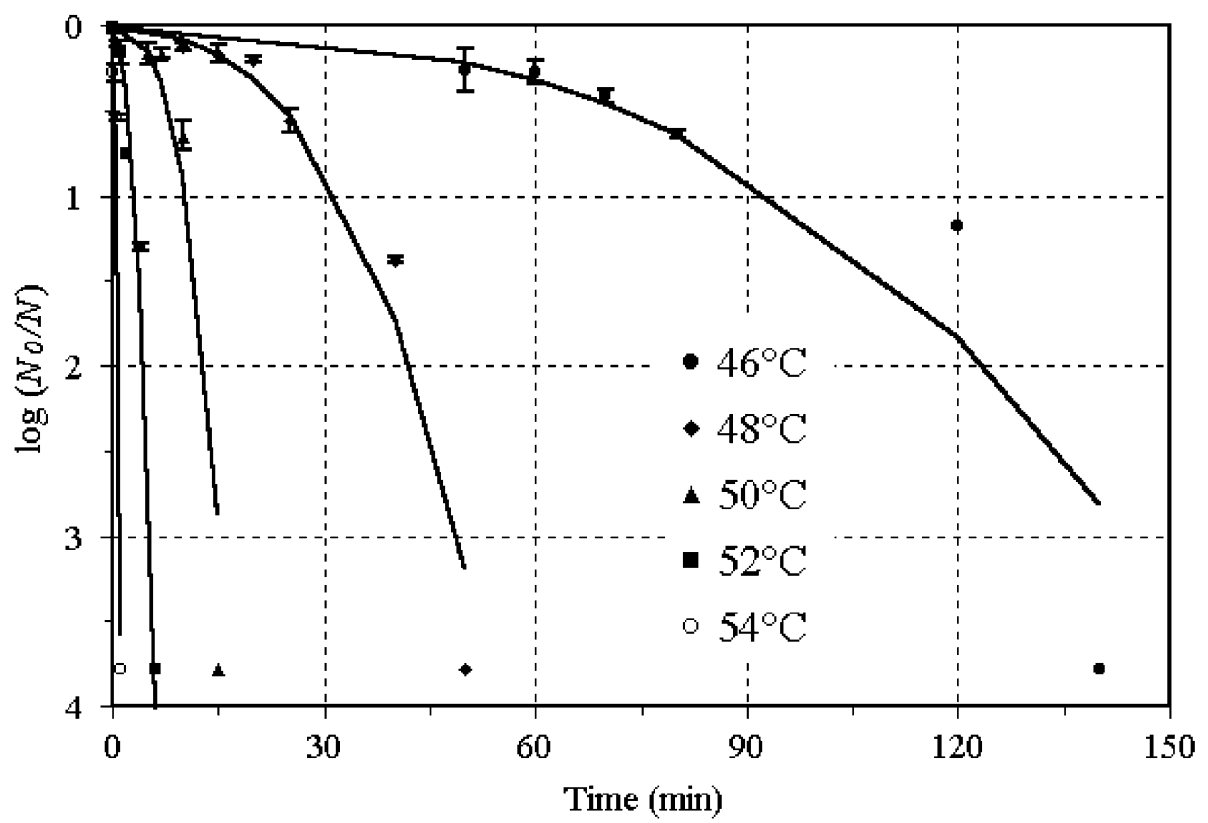

Fig. 4. Thermal-mortality curve of fifth-instar navel orangeworms at different temperatures. Each point represents three samples of 200 larvae and the lines were obtained by regressions. $N_{0}$ and $N$ stand for initial and final live insect numbers. 
Table 1

Thermal-death constants, standard errors (SEs) of the means and determination coefficients $\left(R^{2}\right)$ for fifth-instar navel orangeworms at five temperatures

\begin{tabular}{lllll}
\hline Temp. $\left({ }^{\circ} \mathrm{C}\right)$ & \multicolumn{4}{l}{ Thermal-death constants of $\left(\log \left(N_{0} / N\right)\right)^{a}=k t+c$} \\
\cline { 2 - 5 } & $a$ & $k \pm \mathrm{SE}$ & $c \pm \mathrm{SE}$ & $R^{2}$ \\
\hline 46 & 0.282 & $0.0076 \pm 0.0008$ & $0.2668 \pm 0.065$ & 0.953 \\
48 & 0.282 & $0.0222 \pm 0.0015$ & $0.2770 \pm 0.043$ & 0.977 \\
50 & 0.282 & $0.0764 \pm 0.0077$ & $0.2004 \pm 0.068$ & 0.944 \\
52 & 0.282 & $0.1779 \pm 0.0209$ & $0.4127 \pm 0.065$ & 0.950 \\
54 & 0.282 & $1.0214 \pm 0.2144$ & $0.4114 \pm 0.120$ & 0.919 \\
\hline
\end{tabular}

Table 2

Comparison of lethal times (min) obtained by experiments, empirical (Eq. (1)) and 0.5th-order kinetic models (Eq. (5)) for fifth-instar navel orangeworms at five temperatures

\begin{tabular}{|c|c|c|c|c|c|c|c|c|c|}
\hline \multirow[t]{2}{*}{ Temp. $\left({ }^{\circ} \mathrm{C}\right)$} & \multirow{2}{*}{$\begin{array}{l}\text { Observed } \\
100 \% \\
\text { mortality } \\
\left(\sim \mathrm{LT}_{99.83}\right)\end{array}$} & \multicolumn{4}{|c|}{ Empirical equation } & \multicolumn{4}{|c|}{0.5 th-order kinetic model } \\
\hline & & $\mathrm{LT}_{95}$ & $\mathrm{LT}_{99}$ & $\mathrm{LT}_{99.83}$ & $\begin{array}{l}\mathrm{LT}_{99.9968} \\
\text { (Probit 9) }\end{array}$ & $\mathrm{LT}_{95}$ & $\mathrm{LT}_{99}$ & $\mathrm{LT}_{99.83}$ & $\begin{array}{l}\mathrm{LT}_{99.9968} \\
\text { (Probit 9) }\end{array}$ \\
\hline 46 & 140 & 106.6 & 124.9 & 140.4 & 165.9 & 120.0 & 137.6 & 146.1 & 151.1 \\
\hline 48 & 50 & 36.0 & 42.3 & 47.6 & 56.3 & 40.9 & 46.8 & 49.6 & 51.3 \\
\hline 50 & 15 & 11.5 & 13.3 & 14.8 & 17.4 & 13.5 & 15.3 & 16.2 & 16.8 \\
\hline 52 & 6 & 3.7 & 4.5 & 5.2 & 6.3 & 4.3 & 5.0 & 5.4 & 5.6 \\
\hline 54 & 1 & 0.7 & 0.8 & 0.9 & 1.1 & 0.8 & 0.6 & 1.0 & 1.0 \\
\hline
\end{tabular}

used to predict the mortality of the fifth-instar navel orangeworm when subjected to heat treatments. Table 2 shows that the lethal time to reach a complete kill of 600 insects $\left(\sim \mathrm{LT}_{99.83}\right)$ predicted by the empirical method was in good agreement with experimental results. The established empirical model was further used to predict lethal times for non-quarantine $\left(\mathrm{LT}_{95}, \mathrm{LT}_{99}\right)$ and quarantine treatments $\left(\mathrm{LT}_{99.9968}\right)$ (Table 2). Longer time at lower temperature or shorter time at higher temperature may reach the same level of insect mortality.

The empirical thermal kinetic model (Eq. (1)) was initially used to describe thermal mortality of bacteria (Alderton and Snell, 1970; King et al., 1979) and was adapted by Jang $(1986,1991)$ for investigation of heat treatment efficacy against fruit flies. It is evident that this model is also applicable to fifth-instar codling moths and navel orangeworms and it can be used to estimate the efficacy of a heat treatment when insects are exposed to a constant temperature. However, a major drawback of the empirical model is that it is unable to reveal fundamental information leading to an understanding of the mechanism for thermal kill of insects.

\subsection{TDT curve}

Fig. 5 shows a TDT curve that defines the boundary for $100 \%$ mortality based on the observed exposure time for a complete kill of all test insects $\left(N_{0}=600\right)$ after heating to $46^{\circ} \mathrm{C}, 48^{\circ} \mathrm{C}, 50^{\circ} \mathrm{C}$, $52^{\circ} \mathrm{C}$, and $54^{\circ} \mathrm{C}$ at the heating rate of $18^{\circ} \mathrm{C} \mathrm{min}^{-1}$ (data are also shown in Table 2). In this study, the observed exposure time for $100 \%$ mortality of all 600 test insects corresponded to the 


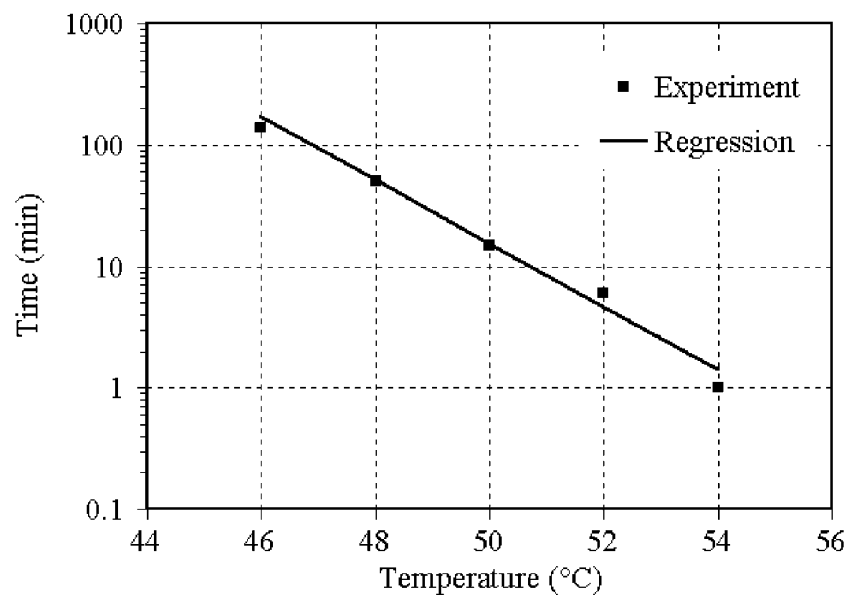

Fig. 5. Thermal-death-time curve for 600 fifth-instar navel orangeworms at a heating rate of $18^{\circ} \mathrm{C} \mathrm{min}{ }^{-1}$. The straight line $(\log t=14.19-0.26 T)$ was obtained by linear regression $\left(R^{2}=0.99\right)$.

estimated lethal times to produce $99.83 \%$ mortality. The longer treatment times needed to achieve acceptable mortality levels $(\geqslant 95 \%)$ for non-quarantine purposes at lower temperatures $\left(46^{\circ} \mathrm{C}\right.$ and $48^{\circ} \mathrm{C}$ ) may not be practical as continuous commercial processes that need to handle large volumes of product. However, more practical treatment times of $<5 \mathrm{~min}$ at higher temperatures $\left(52^{\circ} \mathrm{C}\right.$ and $54^{\circ} \mathrm{C}$ ) provided mortality levels that would be adequate for industrial use. Commercial dehydration of pistachios uses air temperatures of $66-90^{\circ} \mathrm{C}$ for $1 \mathrm{~h}$ with no noticeable effect on product quality (Johnson et al., 1996) and radio frequency treatments on walnuts at $52^{\circ} \mathrm{C}$ for a short time (3 $\mathrm{min}$ ) were acceptable without quality degradation (Wang et al., 2001).

The TDT curve obtained in this study shows that navel orangeworm larvae were more heat resistant than codling moth at the same life-stage (Ikediala et al., 2000). For example, more than $99 \%$ mortality for the fifth-instar codling moth was reached after exposure to $52^{\circ} \mathrm{C}$ for just $2 \mathrm{~min}$ while exposure to $52^{\circ} \mathrm{C}$ for $6 \mathrm{~min}$ was needed to achieve the same mortality for fifth-instar navel orangeworm. The $z$ value for navel orangeworm was found to be about $3.9^{\circ} \mathrm{C}$, which was lower than but very close to that for codling moths $\left(4^{\circ} \mathrm{C}\right)$ (Ikediala et al., 2000).

\subsection{Activation energy}

The activation energy is useful in determining the sensitivity of insects to temperature changes. The activation energy for thermal inactivation of fifth-instar navel orangeworm was calculated using Eq. (3) based on the $z$ value obtained from the TDT curve. The activation energy was $519 \mathrm{~kJ} \mathrm{~mol}^{-1}$, slightly higher than that for codling moth $\left(499 \mathrm{~kJ} \mathrm{~mol}^{-1}\right)$ (Ikediala et al., 2000) and higher than that for thermal inactivation of bacterial spores $\left(210-350 \mathrm{~kJ} \mathrm{~mol}^{-1}\right)$ (Lund, 1977). This value was within the range of the activation energies calculated for eggs and larvae of tephritid fruit flies (400-957 $\mathrm{kJ} \mathrm{mol}^{-1}$ ) (Jang, 1986).

The activation energy also relates the thermal-death-rate constant $k$ in Eq. (1) to temperature changes based on the Arrhenius relationship (Eq. (2)). By plotting the $\log k$ value versus $1 / T$ (Fig. 6), the death-rate constant increased proportionally with $1 / T$. The activation energy as 


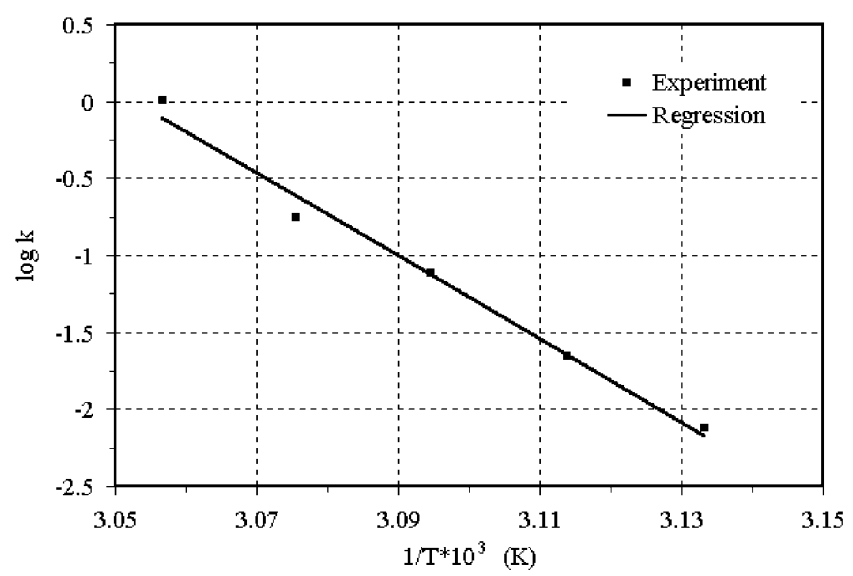

Fig. 6. Arrhenius plot for temperature effects on thermal-death rates of fifth-instar navel orangeworms. The straight line $(\log k=82.21-26.93 * 1000 / T)$ was obtained by linear regression $\left(R^{2}=0.99\right)$.

calculated from the slope of the regression line of the Arrhenius plot $(\log k=82.21-26.93 * 1000 / T$ with $\left.R^{2}=0.99\right)$ was $516 \mathrm{~kJ} \mathrm{~mol}^{-1}$, close to that obtained from the TDT curve $\left(519 \mathrm{~kJ} \mathrm{~mol}^{-1}\right)$.

\subsection{Fundamental kinetic model}

Table 3 shows the coefficients of determination $\left(R^{2}\right)$ at different reaction orders. In general, the 0.5 th-order reaction was most applicable to describe the insect thermal-death curve of fifth-instar navel orangeworm for all temperatures. The thermal-death constants of 0.5 th-order reaction model are shown in Table 4. The value of $k$ obtained from the 0.5 th-order reaction relationship followed an Arrhenius relationship (Eq. (2)) which was expressed as $\log k=81.01-26.65 *$ $1000 / T$ with $R^{2}=0.99$. The obtained activation energy $\left(510 \mathrm{~kJ} \mathrm{~mol}^{-1}\right)$ was very close to that obtained from the TDT curve $\left(519 \mathrm{~kJ} \mathrm{~mol}^{-1}\right)$. The established kinetic model for 0.5 th-order reaction was used to predict the times to reach $95 \%, 99 \%, 99.83 \%$, and $99.9968 \%$ mortality (Table 2). The predicted $\mathrm{LT}_{99.83}$ was close to the experimental results. The predictions show that $<20 \%$ extra time is needed to increase the efficacy of a heat treatment from $99 \%$ mortality to 99.9968\% (Probit 9) when fifth-instar navel orangeworms are exposed to a constant temperature.

Table 3

Determination of the best kinetic order $(n)$ for the thermal kill of fifth-instar navel orangeworm at five temperatures by comparing the coefficients of determination $\left(R^{2}\right)$

\begin{tabular}{llllll}
\hline Temp. $\left({ }^{\circ} \mathrm{C}\right)$ & $n=0$ & $n=0.5$ & $n=1$ & $n=1.5$ & $n=2$ \\
\hline 46 & 0.959 & 0.964 & 0.655 & 0.423 & 0.396 \\
48 & 0.941 & 0.960 & 0.772 & 0.521 & 0.482 \\
50 & 0.944 & 0.900 & 0.698 & 0.587 & 0.577 \\
52 & 0.810 & 0.938 & 0.903 & 0.668 & 0.631 \\
54 & 0.851 & 0.961 & 0.862 & 0.781 & 0.774 \\
\hline
\end{tabular}


Table 4

Thermal death constants of 0.5 th-order reaction model for fifthinstar navel orangeworms at five temperatures

\begin{tabular}{lll}
\hline Temp. $\left({ }^{\circ} \mathrm{C}\right)$ & \multicolumn{2}{l}{ Thermal-death constants of $\left(N / N_{0}\right)^{0.5}=-k t+c$} \\
\cline { 2 - 3 } & $k$ & $c$ \\
\hline 46 & 0.0070 & 1.0633 \\
48 & 0.0209 & 1.0778 \\
50 & 0.0662 & 1.1155 \\
52 & 0.1662 & 0.9323 \\
54 & 0.8881 & 0.9202 \\
\hline
\end{tabular}

In general, the lethal times predicted by the 0.5 th kinetic model were longer than those obtained by the empirical equation for non-quarantine treatments (Table 2). For Probit 9 quarantine treatments, however, the treatment times predicted using the empirical method were longer than those obtained by the 0.5 th fundamental kinetic model. The time difference between the two methods was below $10 \%$ except for $46^{\circ} \mathrm{C}$ in which the large treatment time interval used in mortality tests might have caused the error in the models. Generally, the fundamental kinetic model (Eq. (5)) was simple to obtain and use with the acceptable precision when compared with the empirical equation (Eq. (1)).

Thermal destruction of insect larvae is a complicated process that may be the result of interaction, or damage of several biochemical paths (Neven, 2000). The 0.5th-order reaction determined by the kinetic model may represent an overall reaction that consists of several zero and 1st-order reactions. Further studies are needed to understand the thermal-destruction mechanism that governs this overall 0.5 th-order reaction for thermal kill of the fifth-instar navel orangeworm, and to link the activation energy $\sim 500 \mathrm{~kJ} \mathrm{~mol}^{-1}$ to related fundamental physiological pathways leading to the thermal kills.

\section{Conclusions}

An improved heating block system was developed to study the thermal mortality of fifth-instar navel orangeworms. Complete kill of 600 insects was achieved with a minimum exposure time of $140,50,15,6$, and $1 \mathrm{~min}$ at $46^{\circ} \mathrm{C}, 48^{\circ} \mathrm{C}, 50^{\circ} \mathrm{C}, 52^{\circ} \mathrm{C}$, and $54^{\circ} \mathrm{C}$, respectively. Fifth-instar navel orangeworm were more heat resistant than fifth-instar codling moths (Ikediala et al., 2000). The thermal-death curves for fifth-instar navel orangeworms were modeled both by an empirical equation and by the fundamental kinetic models. For the fundamental kinetic model, we examined $0-, 0.5$ th-, 1st-, 1.5th, and 2nd-order reaction, and determined that the 0.5 th-order reaction model best described thermal-mortality data of the insects. In general, the lethal times predicted by the 0.5 th-order kinetic model were more conservative than those obtained by the empirical equation for non-quarantine treatments. The 0.5 th-order kinetic model was also simple to obtain and use with the acceptable precision when compared with the empirical equation. The reaction rate $(k)$ as a function of treatment temperatures followed an Arrhenius relationship. The activation energy for thermal kill of fifth-instar navel orangeworm was between 510 and 
$520 \mathrm{~kJ} \mathrm{~mol}^{-1}$. This thermal-death kinetic information should be useful for the development of thermal methods for post-harvest control of fifth-instar navel orangeworms in nuts.

\section{Acknowledgements}

This research was supported by grants from USDA-NRI and USDA IFAFS programs, and from Washington State University IMPACT Center. We thank Karen Valero (USDA-ARS, Fresno, CA) for her technical assistance. We also thank Guy Hallman, Lisa Neven, and Barbara Waddell for reviewing this manuscript and their constructive suggestions.

\section{References}

Alderton, G., Snell, N., 1970. Chemical states of bacterial spores: heat resistance and its kinetics at intermediate water activity. Applied Microbiology 19, 565-572.

Andreuccetti, D., Bini, M., Ignesti, A., Gambetta, A., Olmi, R., 1994. Microwave destruction of woodworms. Journal of Microwave Power and Electromagnetic Energy 29, 153-160.

Brandl, D.G., Soderstrom, E.L., Schreiber, F.E., 1983. Effects of low-oxygen atmospheres containing different concentrations of carbon dioxide on mortality of the navel orangeworm, Amyelois transitella Walker (Lepidoptera: Pyralidae). Journal of Economic Entomology 76, 828-830.

Carpenter, J., Gianessi, L., Lynch, L., 2000. The economic impact of the scheduled US phaseout of methyl bromide. National Center for Food and Agricultural Policy, Washington, DC.

Hallman, G.J., Sharp, J.L., 1994. Radio frequency heat treatments. In: Sharp, J.L., Hallman, G.J. (Eds.), Quarantine Treatments for Pests of Food Plants. Westview Press, San Francisco, CA, pp. 165-170.

Ikediala, J.N., Tang, J., Wig, T., 2000. A heating block system for studying thermal death kinetics of insect pests. Transaction of the American Society of Agricultural Engineers 43, 351-358.

Jang, E.B., 1986. Kinetics of thermal death in eggs and first instars of three species of fruit flies (Diptera: Tephritidae). Journal of Economic Entomology 79, 700-705.

Jang, E.B., 1991. Thermal death kinetics and heat tolerance in early and late third instars of the oriental fruit fly (Diptera: Tephritidae). Journal of Economic Entomology 84, 1298-1303.

Johnson, J.A., Marcotte, M., 1999. Irradiation control of insect pests of dried fruits and walnuts. Food Technology 53, $46-51$.

Johnson, J.A., Gill, R.F., Valero, K.A., May, S.A., 1996. Survival of navel orangeworm (Lepidoptera: Pyralidae) during pistachio processing. Journal of Economic Entomology 89, 197-203.

Johnson, J.A., Valero, K.A., Hannel, M.M., 1997. Effect of low temperature storage on survival and reproduction of Indianmeal moth (Lepidoptera: Pyralidae). Crop Protection 16, 519-523.

Johnson, J.A., Vail, P.V., Soderstrom, E.L., Curtis, C.E., Brandl, D.G., Tebbets, J.S., Valero, K.A., 1998. Integration of nonchemical postharvest treatments for control of navel orangeworm (Lepidoptera: Pyralidae) and Indianmeal moth (Lepidoptera: Pyralidae) in walnuts. Journal of Economic Entomology 91, 1437-1444.

Jones, V.M., Waddell, B.C., 1997. Effect of hot water on mortality of Cydia pomonella (Lepidoptera: Tortricidae). Journal of Economic Entomology 90, 1357-1359.

King, A.D., Bayne, H.G., Alderton, G., 1979. Non-logarithmic death rate calculations for Byssochlamys fulva and other microorganisms. Applied Environment Microbiology 37, 596-600.

Lund, D.B., 1977. Design of thermal processes for maximizing nutrient retention. Food Technology 31, 71-78.

Lurie, S., 1998. Postharvest heat treatments. Postharvest Biology and Technology 14, 257-269.

Nelson, S.O., 1996. Review and assessment of radio-frequency and microwave energy for stored-grain insect control. Transaction of the American Society of Agricultural Engineers 39, 1475-1484.

Neven, L.G., 2000. Physiological response of insects to heat. Postharvest Biology and Technology 21, 103-111. 
Storey, C.L., Soderstrom, E.L., 1977. Mortality of navel orangeworm in a low-oxygen atmosphere. Journal of Economic Entomology 70, 95-97.

Tang, J., Ikediala, J.N., Wang, S., Hansen, J.D., Cavalieri, R.P., 2000. High-temperature-short-time thermal quarantine methods. Postharvest Biology and Technology 21, 129-145.

Tebbets, J.S., Curtis, C.E., Fries, R.D., 1978. Mortality of immature stages of the navel orangeworm stored at $3.5^{\circ} \mathrm{C}$. Journal of Economic Entomology 71, 875-876.

Thomas, D.B., Mangan, R.L., 1997. Modeling thermal death in the Mexican fruit fly (Diptera: Tephritidae). Journal of Economic Entomology 90, 527-534.

United Nations Environmental Programme (UNEP), 1992. Proceedings of the Fourth Meeting of the Parties to the Montreal Protocol on Substances that Deplete the Ozone Layer, Copenhagen, 23-25 November 1992. UNEP, Nairobi, Kenya.

United States Department of Agriculture (USDA), 1999. Agricultural Statistics. USDA, Washington, DC.

United States Environmental Protection Agency (USEPA), 1998. Reregistration Eligibility Decision. Aluminum and Magnesium Phosphide. Cases 0025 \& 0645. Special Review and Reregistration Division, Office of Pesticide Programs, USEPA.

Wade, W.H., 1961. Biology of the navel orangeworm, Paramyelois transitella (Walker), on almonds and walnuts in northern California. Hilgardia 31, 129-170.

Waddell, B.C., Jones, V.M., Petry, R.J., Sales, F., Paulaud, D., Maindonald, J.H., Laidlaw, W.G., 2000. Thermal conditioning in Bactrocera tryoni eggs (Diptera: Tephritidae) following hot-water immersion. Postharvest Biology and Technology 21, 113-128.

Wang, S., Ikediala, J.N., Tang, J., Hansen, J.D., Mitcham, E., Mao, R., Swanson, B., 2001. Radio frequency treatments to control codling moth in in-shell walnuts. Postharvest Biology and Technology 22, 29-38.

Yokoyama, V.Y., Miller, G.T., Dowell, R.V., 1991. Response of codling moth (Lepidoptera: Tortricidae) to high temperature, a potential quarantine treatment for exported commodities. Journal of Economic Entomology 84, $528-531$.

Zettler, J.L., Halliday, W.R., Arthur, F.H., 1989. Phosphine resistance in insects infesting stored peanuts in the southeastern United States. Journal of Economic Entomology 82, 1508-1511. 